\title{
Animal model evaluation of a novel renal denervation system for future laparoscopic treatment of resistant hypertension
}

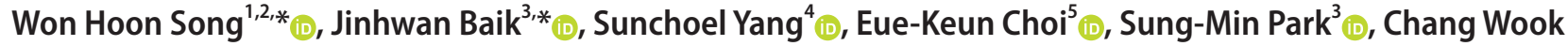 \\ Jeong ${ }^{1}$ (i) \\ ${ }^{1}$ Department of Urology, Seoul National University Hospital, Seoul, ${ }^{2}$ Department of Urology, Pusan National University Yangsan Hospital, Yangsan, ${ }^{3}$ Department of \\ Creative IT Engineering, Pohang University of Science and Technology (POSTECH), Pohang, ${ }^{4}$ Department of Prototype Production, Osong Medical Innovation Foundation, \\ Cheongju, ${ }^{5}$ Department of Internal Medicine, Seoul National University Hospital, Seoul, Korea
}

Purpose: Although percutaneous catheter-based ablation of renal sympathetic nerve fibers has been used in the treatment of patients with resistant hypertension, a recent phase III study did not confirm its efficacy. In this study, we developed a novel laparoscopic renal denervation system and evaluated its safety and initial feasibility using an animal model.

Materials and Methods: A novel surgical instrument that uses a smart algorithm with temperature-monitoring feedback was developed. We used 4 male pigs ( 6 weeks old, weighing approximately $45 \mathrm{~kg}$ each) to evaluate the safety and efficacy of the laparoscopic renal denervation system. We performed immunohistochemical staining analysis after renal denervation using various tip temperatures and over various durations through an open approach.

Results: When the temperature of the outer wall of the renal artery was maintained at $90^{\circ} \mathrm{C}$ for 180 seconds, the artery was completely denervated without damaging its inner layer, as evaluated using Masson's trichrome staining. When the temperature ranged from $70^{\circ} \mathrm{C}$ to $90^{\circ} \mathrm{C}$ and the duration ranged from 90 to 420 seconds, partial or complete denervation without significant vessel injury was confirmed with anti- growth-associated protein 43 and anti-S100 staining.

Conclusions: This animal study confirmed the safety and feasibility of the novel laparoscopic renal denervation system. A safe and effective protocol was developed with ablation at a constant tissue temperature of $70^{\circ} \mathrm{C}$ to $90^{\circ} \mathrm{C}$ within 180 seconds. However, further developments are necessary before its clinical use.

Keywords: Animals; Denervation; Hypertension; Laparoscopy; Renal artery

This is an Open Access article distributed under the terms of the Creative Commons Attribution Non-Commercial License (http://creativecommons.org/licenses/by-nc/4.0) which permits unrestricted non-commercial use, distribution, and reproduction in any medium, provided the original work is properly cited.

\section{INTRODUCTION}

According to the World Health Organization, $40 \%$ of the adult population older than 25 years have hypertension, which results in 10 million deaths annually [1,2]. A recent systematic review and meta-analysis of 24 studies indicated that $14 \%$ to $16 \%$ of hypertensive patients worldwide (approximately 140 to 160 million people) are resistant to antihypertensive drugs [3].

Renal denervation $(\mathrm{RDN})$ is a novel nonpharmacologic

Received: 2 June, 2019 - Accepted: 13 August, 2019

Corresponding Author: Chang Wook Jeong (iD https://orcid.org/0000-0002-2200-5019

Department of Urology, Seoul National University Hospital, 101 Daehak-ro, Jongno-gu, Seoul 03080, Korea

TEL: +82-2-2072-3899, FAX: +82-2-742-4665, E-mail: drboss@gmail.com

*These authors contributed equally to this study and should be considered co-first authors. 
intervention that locks the sympathetic nerves around the renal artery via the insertion of an electrode through a percutaneous catheter to reduce blood pressure [4-7]. However, SYMPLICITY HTN-3 (a recent large-scale, single-blind, randomized controlled trial) reported that the group treated using catheter-based ablation did not achieve a significant decrease in blood pressure compared with the sham group [8,9]. In addition, because the sympathetic nerve fibers around the renal artery were distributed far from the arterial wall, a catheter-based ablation would not be sufficiently effective [10]. In our animal model and human tissue studies, we found that the sympathetic nerve fibers were located 3 to 5 $\mathrm{mm}$ from the luminal surface and $8 \mathrm{~mm}$ from the center of the renal artery $[11,12]$. In addition, according to renal angiographic studies using computed tomography angiography, more than $30 \%$ of patients had anatomical variants of renal arteries, such as an accessory artery and early branching arteries [13]. Because the conventional catheter-based ablation is performed only for the main artery [14], complete denervation is not possible if there are many accessory arteries and nerve fibers far from the center of the renal artery [12]. Therefore, a novel laparoscopic RDN system $\left(360^{\circ}\right.$ wrapping of the renal artery) that can completely ablate multiple renal arteries with additional surgical denervation for patients resistant to hypertension treatment was previously proposed, and its feasibility has been confirmed through simulations and in vitro experiments [15]. The laparoscopic approach is also advantageous because of the easy access to the renal artery located behind the renal vein and the lack of peritoneal violation [16-18]. However, because it is difficult to obtain a visual field for the nerves around the artery on the opposite side of the camera, which are difficult to remove and may result in damage to the artery wall, this procedure requires surgical expertise. Thus, our method of wrapping the looped electrode outside the artery might decrease arterial wall injury compared with the percutaneous catheter-based method or laparoscopic surgical dissection.

In this study, we used an animal model to examine the denervation efficacy, safety, and protocol of the novel laparoscopic RDN system in terms of denervation and injury of the renal arteries and adjacent tissues, to contribute to the development of innovative treatments for patients with resistant hypertension.

\section{MATERIALS AND METHODS}

\section{Study design}

This study was approved by the appropriate Institutional Animal Care and Use Committees of Seoul National Uni- versity Hospital (approval number: 17-0202-S1A0(3)). A prototype of the novel laparoscopic RDN system was used for the renal arteries of 4 pig models to confirm the initial clinical feasibility in terms of safety and denervation efficacy. The pig is a common animal used for surgical kidney models because of the similarities in the size and location of the kidneys between pigs and humans [19,20]. During this first animal experiment, we selected at least 8 tests for 4 pigs (bilateral tests in each pig) using a 2-plus-2 step-up design after obtaining approval from the Institutional Animal Care and Use Committees. After finishing the experiment with 2 pigs, we selected the protocol to be tested with the other 2 pigs.

\section{Novel surgical instrumentation}

Fig. 1 shows a schematic illustration of the proposed laparoscopic RDN surgical instrument. The proposed instrument needs to envelop the outer wall of the renal artery for complete denervation and to focus heat energy on the outer wall to minimize arterial damage. To satisfy these requirements, our group chose bipolar instruments that consisted of parallel-tip electrodes and a round plate, as demonstrated by simulations in a previous study [15]. This method was designed to deliver radiofrequency (RF) energy to renal nerves through parallel-tip electrodes (length, $55 \mathrm{~mm}$; width, $1 \mathrm{~mm}$; depth, $0.05 \mathrm{~mm}$; separated by $2 \mathrm{~mm}$ ). The current loop was generated between the parallel-tip electrodes, and the density associated with the increased tissue temperature was more concentrated in the outer wall of the renal arteries than in the inner wall. The tip on the round plate was wrapped $360^{\circ}$ around the renal artery. This prototype tip has elastic properties that allow maintaining its round shape after it is slightly unrolled. The operators slightly unrolled the surgical tip to wrap the renal artery and then unrolled the tip again to remove it after the ablation was completed. To use this tool as a bipolar electrosurgical device, the parallel tip electrodes were not placed in contact with the round plate; however, the tip was in direct contact with the tissue to create a current loop. All sides of the plate were coated with polyamide. The plate and electrodes are composed of stainless steel. Finally, a fiber-optic temperature probe was placed between the parallel electrodes. This prototype was made for the current experiment. The final version of this laparoscopic device will have more sophisticated functionalities (such as loop control for opening and closing).

\section{Experimental setup}

Fig. 2 shows the experimental laparoscopic RDN system. The RDN surgical instrument delivers electrical energy when an electrical signal is generated by a function genera- 

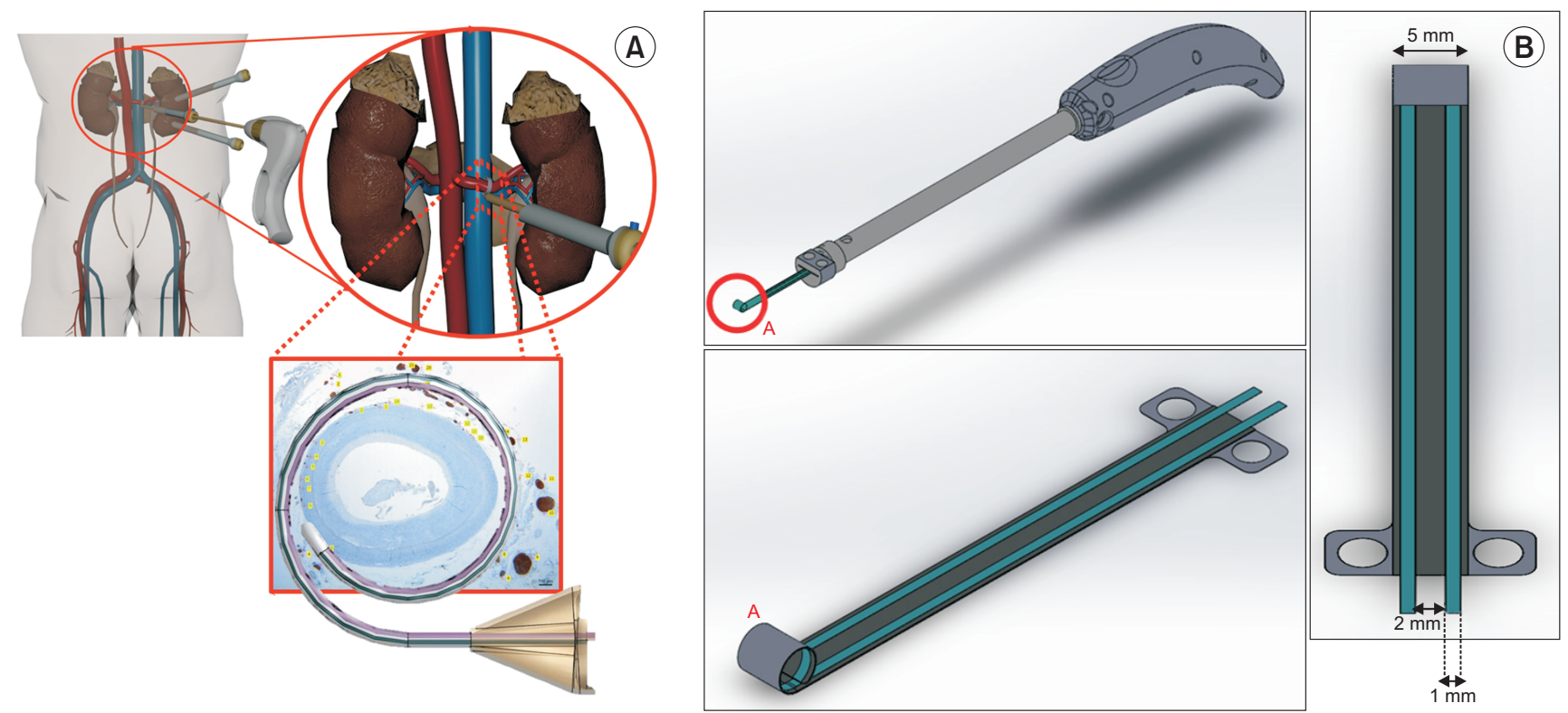

Fig. 1. (A) Schematic of the proposed laparoscopy-based renal denervation (RDN) surgical approach and (B) concept design of the surgical instrument for laparoscopy-based RDN. A, curling tip of RDN device.
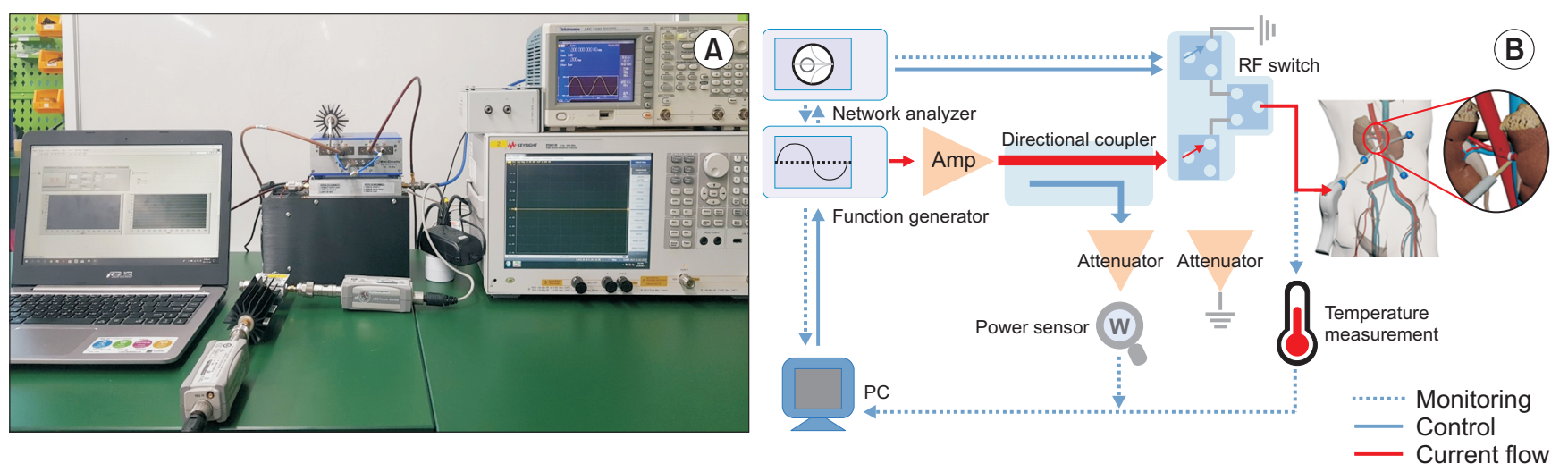

Fig. 2. Real-time energy delivery-controlling generator (A) using a smart algorithm with temperature-monitoring feedback (B). RF, radiofrequency; Amp, amplifier.

tor and is amplified through an RF amplifier. This instrument measures incident power, load impedance, and the temperature of the tip. A directional coupler and power sensors are placed between the $\mathrm{RF}$ amplifier and the instrument to measure the incident power. A network analyzer measures impedance between parallel electrodes. To measure the increase in temperature of the tissue touching the electrode tip during RF injection, a fiber-optic temperature probe is used because it has electromagnetic interference and highvoltage immunity.

The system was operated in the temperature-control mode, which kept the arterial wall at a constant temperature via feedback control. Temperature monitoring is essential for obtaining feedback data and controlling the delivered electrical energy. The recorded temperature, as an input value of the feedback algorithm, affects the duration of RF switching, which modulates the amount of incident electrical energy. In this study, we used Labview (National Instruments, Cos Cob, CT, USA) to control the RF devices and monitoring devices.

\section{Experiment using an animal model}

Fig. 3 shows the animal model used for the evaluation of the novel surgical instrument for laparoscopic RDN. A total of 4 male pigs weighing approximately $45 \mathrm{~kg}$ were fasted for 12 hours on the day before surgery. Before surgery, $0.06 \mathrm{~mL} /$ kg Tardomyocel Comp. III (an antibiotic, Bayer Korea) was intramuscularly injected. Intubation was performed under isoflurane general anesthesia. In this study, we performed open surgery by creating a mid-line incision; however, the 


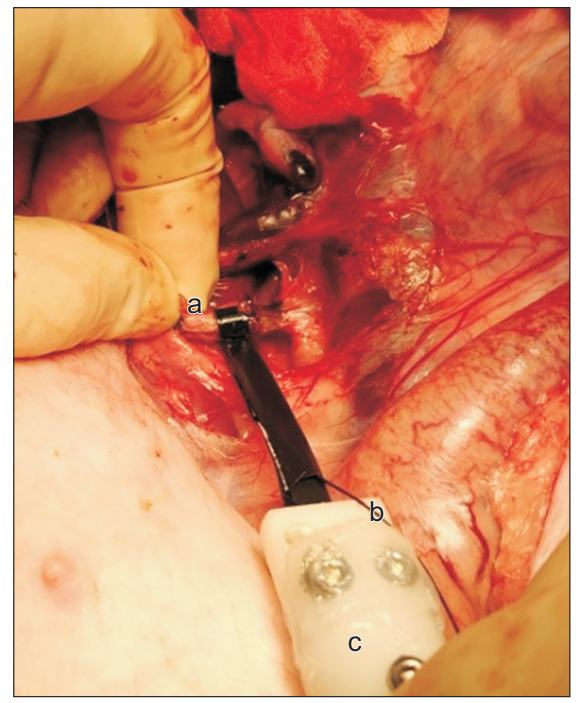

Fig. 3. Animal experiment using the novel surgical instrument for laparoscopy-based renal denervation (RDN). ${ }^{\mathrm{a}}$ :The electrode is wrapped $360^{\circ}$ around the artery. ${ }^{\mathrm{b}}$ :Temperature wire electrode. ${ }^{\mathrm{c}}$ :Surgical instrument for laparoscopy-based RDN. novel laparoscopic RDN system is applicable to both open and laparoscopic surgery. Table 1 shows the results of the denervation protocol using the novel laparoscopic RDN system. After performing the first 2 tests involving animals 1 and 2, the experimental protocols for animals 3 and 4 were established. The first test was performed with 2 animals and involved a tissue temperature of $70^{\circ} \mathrm{C}$ to $90^{\circ} \mathrm{C}$ and an ablation duration of 90 to 240 seconds in the temperature-control mode. Because the first animal test showed only partial denervation in multiple settings, the second animal test was performed using an optimized electrode temperature of $90^{\circ} \mathrm{C}$ to enhance the efficacy. Thereafter, tissues were harvested and fixed in $4 \%$ formalin for 24 to 48 hours. The tissues were embedded in paraffin and cut in the sagittal plane to a thickness of $4 \mu \mathrm{m}$ to create the slide. The overall histology of the denervated tissue was identified using hematoxylin and eosin (H\&E) staining, and vascular damage including that of the intimal layer was assessed using Masson's trichrome

Table 1. Denervation protocol for animal experiments using the novel laparoscopy-based renal denervation system and summary of denervation results

\begin{tabular}{|c|c|c|c|c|c|c|c|c|c|}
\hline Pig & Laterality & $\begin{array}{l}\text { Length } \\
(\mathrm{mm})\end{array}$ & $\begin{array}{l}\text { Diameter } \\
\text { (mm) }\end{array}$ & $\begin{array}{l}\text { Location of the renal } \\
\text { artery for denervation } \\
\text { (distal or proximal } \\
\text { segment) }\end{array}$ & $\begin{array}{l}\text { Temperature } \\
\left({ }^{\circ} \mathrm{C}\right)\end{array}$ & $\begin{array}{l}\text { Duration } \\
\text { time }(s)\end{array}$ & $\begin{array}{l}\text { Summary of } \\
\text { denervation } \\
\text { results }\end{array}$ & $\begin{array}{c}\text { Remarkable findings } \\
\text { from the denervated } \\
\text { sample }\end{array}$ & $\begin{array}{c}\text { Final report of } \\
\text { denervation }\end{array}$ \\
\hline \multirow[t]{2}{*}{1} & Left & 22 & 6 & Proximal & 80 & 120 & Partial & $\begin{array}{l}\text { Contact problem between } \\
\text { tissues and electrodes }\end{array}$ & Unsuccessful \\
\hline & & & & Distal & 80 & 90 & Partial & $\begin{array}{l}\text { Contact problem between } \\
\text { tissues and electrodes }\end{array}$ & \\
\hline 1 & Right & 22 & 6 & Proximal & 80 & 240 & Complete & $\begin{array}{l}\text { All structures of nerves } \\
\text { with connective tissue } \\
\text { removed clearly }\end{array}$ & Successful \\
\hline \multirow[t]{2}{*}{2} & Left & 30 & 6 & Proximal & 90 & 120 & Partial & $\begin{array}{l}\text { Lack of energy } \\
\text { transmission }\end{array}$ & Unsuccessful \\
\hline & & & & Distal & 90 & 90 & Partial & $\begin{array}{c}\text { Contact problem between } \\
\text { tissues and electrodes }\end{array}$ & \\
\hline \multirow[t]{2}{*}{2} & Right & 20 & 7 & Proximal & 70 & 120 & Partial & $\begin{array}{l}\text { Contact problem between } \\
\text { tissues and electrodes }\end{array}$ & Unsuccessful \\
\hline & & & & Distal & 70 & 90 & Partial & $\begin{array}{l}\text { Lack of energy } \\
\text { transmission }\end{array}$ & \\
\hline \multirow[t]{2}{*}{3} & Right & 20 & 5 & Proximal & 90 & 420 & Complete & & Successful \\
\hline & & & & Distal & 90 & 420 & Complete & & \\
\hline \multirow[t]{2}{*}{4} & Left & 20 & 6 & Proximal & 90 & 300 & Partial & $\begin{array}{l}\text { Lack of energy } \\
\text { transmission }\end{array}$ & Successful \\
\hline & & & & Distal & 90 & 300 & Complete & $\begin{array}{l}\text { All structures of nerves } \\
\text { with connective tissue } \\
\text { removed clearly }\end{array}$ & \\
\hline \multirow[t]{2}{*}{4} & Right & 20 & 5 & Proximal & 90 & 180 & Complete & $\begin{array}{l}\text { All structures of nerves } \\
\text { with connective tissue } \\
\text { removed clearly }\end{array}$ & Successful \\
\hline & & & & Distal & 90 & 180 & Complete & $\begin{array}{l}\text { All structures of nerves } \\
\text { with connective tissue } \\
\text { removed clearly }\end{array}$ & \\
\hline
\end{tabular}


(MT) staining. Immunohistochemical staining with each antibody against tyrosine hydroxylase (TH) (mouse monoclonal anti-TH; Accurate Chemical, Westbury, NY, USA), choline acetyltransferase (goat anti-choline acetyltransferase polyclonal antibody; Chemicon, Billerica, MA, USA), growthassociated protein 43 (mouse anti-GAP43 monoclonal antibody; Chemicon), and anti-S100 antibody (Boster Biological Technology, Pleasanton, CA, USA) was performed to assess necrosis, denaturation, and denervation of the nerve and artery $[10,21]$. Complete denervation was defined as the absence of any remaining nerve fibers in the stained slide, and partial denervation was defined as the presence of 1 or more non-ablated nerve fibers. The denervation was defined as successful when laparoscopic RDN was completed in either the proximal or distal segment of the artery and all nerve activity was blocked.

\section{RESULTS}

Supplementary Fig. 1 shows the impedance and temperature profiles of the electrode and the histologic results of denervation for 3 minutes at a temperature at $90^{\circ} \mathrm{C}$. During ablation, the temperatures of the tissues touching the electrode (approximately $90^{\circ} \mathrm{C}$ ) and surrounding blood vessels (approximately $37^{\circ} \mathrm{C}$ ) remained relatively constant, except that the tissue temperature suddenly decreased after approximately 100 seconds (Supplementary Fig. 1A). The temperature profile also increased to $90^{\circ} \mathrm{C}$ within 10 seconds and remained relatively constant for 3 minutes thereafter. $\mathrm{H} \& \mathrm{E}$ staining confirmed the overall structure of the completely denervated renal artery (Supplementary Fig. 1C), and immunohistochemical staining with anti-TH antibody showed complete denervation of sympathetic nerve fibers outside the renal artery (Supplementary Fig. 1D-F). In addition, MT staining revealed no damage to the inner layers of the renal artery (Supplementary Fig. 1G). The clear removal of the entire nerve and connective tissue structures was remarkable.

Supplementary Fig. 2 shows the ablation of the renal artery performed for 7 minutes while maintaining the temperature of the electrode at $90^{\circ} \mathrm{C}$, with as much fat tissue as possible remaining in the distal portion of the right renal artery. During ablation, the temperature of the electrode (approximately $90^{\circ} \mathrm{C}$ ) and surrounding blood vessels (approximately $32^{\circ} \mathrm{C}$ ) remained relatively constant (Supplementary Fig. 2A). The RF profile also increased to $90^{\circ} \mathrm{C}$ within 10 seconds and remained relatively constant for 7 minutes thereafter. Supplementary Fig. 2B-D shows the longitudinal section of the renal artery with H\&E staining (Supplementary Fig. 2B), TH staining (Supplementary Fig. 2C), and immunohistochemical staining with anti-GAP43 antibody (Supplementary Fig. 2D). Some sympathetic nerve bundles inside the fat tissue remained without denervation or partial denervation, thus showing focal loss of immunopositivity for neurofilament protein (red arrows) [22]. Supplementary Fig. 2E shows tissues that were immunohistochemically stained with anti-S100 antibody. Some sympathetic nerves inside the fat tissue area that was not in contact with the electrode were partially denervated, indicating destruction of the Schwann cells of the nerves (red arrows) [10]. However, some completely ablated areas blocked the electrical conduction in the longitudinal section, which indicated a successful denervation.

Supplementary Fig. 3 shows the results of the denervation at $80^{\circ} \mathrm{C}$ for 90 seconds (Supplementary Fig. 3A, B) and at $90^{\circ} \mathrm{C}$ for 90 seconds (Supplementary Fig. 3C, D), followed by immunohistochemical staining with anti-S100 antibody. Some sympathetic nerves in the remaining fat tissue around the renal artery were not denervated or were partially denervated, and showed focal loss of immunopositivity for neurofilament protein and destruction of the Schwann cells of the nerves (red arrows) [10].

Table 1 summarizes the denervation results. An electrode temperature higher than $90^{\circ} \mathrm{C}$ and a denervation duration longer than 180 seconds resulted in more denervation. There were no vital sign changes, adverse events, or gross injury to the surrounding tissues during the procedures.

\section{DISCUSSION}

This is the first study to investigate the safety and feasibility of complete RDN through animal experiments using a novel laparoscopic RDN system. A minimally invasive laparoscopic RDN system that wraps $360^{\circ}$ around the renal artery and that could be applied to the retroperitoneal laparoscopic approach, allowing easy access to the renal hilum without intraperitoneal puncture or bowel injury. Its applicability has been demonstrated using simulations and in vitro studies in animal models [15].

Compared with the incomplete denervation of conventional catheter-based ablation, our proposed system that envelops the renal artery $360^{\circ}$ could completely ablate not only the sympathetic nerves near the arterial wall but also the distant nerves [22]. The results of denervation in the temperature-control mode at $90^{\circ} \mathrm{C}$ for 420 seconds showed that the sympathetic nerve fibers surrounding the renal arteries were completely denervated, as evaluated using HE staining and immunohistochemical staining with anti-TH antibody. In addition, complete denervation without arterial damage 
was possible at an electrode temperature of $90^{\circ} \mathrm{C}$ for a duration of more than 420 seconds, except in some samples. However, it was uncertain whether the clear removal of connective tissues around the arteries was due to the denervation effect or the removal of tissues during dissection. Therefore, the temperature-control mode may be suitable for ablating nerve bundles on the arterial surface.

In Supplementary Fig. 1A, load impedance includes not only the impedance of the tissue but also the resistance between the parallel electrodes of the surgical instrument. The contact status between tissues and surgical instruments is shown. The increase in load impedance indicated that the surgical instrument was not fully in contact with the tissue, and the decrease in load impedance indicated that the surgical instrument and tissues were connected and in a state that allows the full application of RF energy. Supplementary Fig. $2 \mathrm{~A}$ shows that the temperature of the electrodes suddenly decreased after approximately 100 seconds and that the load impedance increased. This was an intraoperative problem involving poor contact between the electrodes of the instrument and the tissue. Because the general method of electrosurgery involves lowering the impedance, we slightly reduced the normal saline volume and maintained the electrode temperature at $90^{\circ} \mathrm{C}$.

After treatment, it was found that the nerves surrounding the connective tissues beyond the electrode width of 5 $\mathrm{mm}$ were not properly ablated. This damage to the tissues, which occurred only within the width of the electrodes, was advantageous because only the target point was ablated and other tissues were not damaged. The arteries containing many connective tissues in this animal experiment were not uniform circles.

This study has several limitations. First, this study showed the possibilities of laparoscopic RDN and found that the temperature-control mode could minimize arterial damage. However, there was no definite correlation between operative temperature, duration, applied energy, nerve ablation, and arterial wall injury. Second, in this study, we first histologically assessed whether the sympathetic nerves surrounding the renal artery were safely denervated without arterial injury by our novel RDN system. Thereafter, we established an optimal energy transmission protocol. In the future, we plan to develop a real-world miniaturized laparoscopic instrument and perform a preclinical study to identify changes in blood pressure, which is the final biological alteration, in an acute hypertensive animal and survival model.

Because our novel denervation system was developed for a laparoscopic approach, it may be difficult to perform com- plete denervation as easily as with an open approach. However, we aimed to develop a system that is not affected by the learning curve of the operators and that is safe and easy to use, with equally effective results, for both specialists and novices. The surgical denervation and laparoscopic denervation equipment and systems described in this study can overcome the limitations of the conventional catheter-based $\mathrm{RDN}$ and result in more complete and safer denervation.

\section{CONCLUSIONS}

The safety and efficacy of the novel laparoscopic RDN system with electrodes that wrap $360^{\circ}$ around the renal arteries in an animal model require verification. Determining the appropriate temperature and duration in the temperature-control mode can allow denervation of the renal sympathetic nerve fibers that are distributed in a nearly complete circle, without damaging the surrounding tissues or arteries. In the future, it will be necessary to develop a device with a shape and size suitable for actual surgery and to add a function that allows the operator to tighten or adjust the loop size of the electrode.

\section{CONFLICTS OF INTEREST}

This novel laparoscopic renal denervation system was invented by Chang Wook Jeong and Sung-Min Park.

\section{ACKNOWLEDGMENTS}

This research was supported by a grant from the Korea Health Technology R\&D Project through the Korea Health Industry Development Institute and funded by the Ministry of Health \& Welfare, Republic of Korea (grant no. HI17C1314).

\section{AUTHORS' CONTRIBUTIONS}

Research conception and design: Eue-Keun Choi, SungMin Park, and Chang Wook Jeong. Data acquisition: All authors. Statistical analysis: Won Hoon Song and Jinhwan Baik. Data analysis and interpretation: Won Hoon Song, Jinhwan Baik, Sung-Min Park, and Chang Wook Jeong. Drafting of the manuscript: Won Hoon Song and Jinhwan Baik. Critical revision of the manuscript: All authors. Obtaining funding: Sunchoel Yang, Sung-Min Park, and Chang Wook Jeong. Administrative, technical, or material support: Eue-Keun Choi and Chang Wook Jeong. Supervision: Chang Wook Jeong. Approval of the final manuscript: all authors. 


\section{SUPPLEMENTARY MATERIALS}

Scan this QR code to see the supplementary materials, or visit https://www.icurology.org/src/sm/icurology-61-107-s001.pdf.

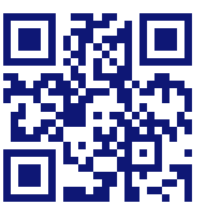

\section{REFERENCES}

1. GBD 2015 Risk Factors Collaborators. Global, regional, and national comparative risk assessment of 79 behavioural, environmental and occupational, and metabolic risks or clusters of risks, 1990-2015: a systematic analysis for the Global Burden of Disease Study 2015. Lancet 2016;388:1659-724.

2. World Health Organization. A global brief on hypertension: silent killer, global public health crisis [Internet]. Geneva: WHO; 2013 [cited 2018 Jun 4]. Available from: https://www.who.int/ cardiovascular_diseases/publications/global_brief_hypertension/en/

3. Achelrod D, Wenzel U, Frey S. Systematic review and metaanalysis of the prevalence of resistant hypertension in treated hypertensive populations. Am J Hypertens 2015;28:355-61.

4. Tsioufis CP, Papademetriou V, Dimitriadis KS, Kasiakogias A, Tsiachris D, Worthley MI, et al. Catheter-based renal denervation for resistant hypertension: twenty-four month results of the EnligHTN I first-in-human study using a multi-electrode ablation system. Int J Cardiol 2015;201:345-50.

5. Krum H, Schlaich M, Whitbourn R, Sobotka PA, Sadowski J, Bartus $\mathrm{K}$, et al. Catheter-based renal sympathetic denervation for resistant hypertension: a multicentre safety and proof-ofprinciple cohort study. Lancet 2009;373:1275-81.

6. Gordan R, Gwathmey JK, Xie LH. Autonomic and endocrine control of cardiovascular function. World J Cardiol 2015;7:20414.

7. Chen PS, Chen LS, Fishbein MC, Lin SF, Nattel S. Role of the autonomic nervous system in atrial fibrillation: pathophysiology and therapy. Circ Res 2014;114:1500-15.

8. Flack JM, Bhatt DL, Kandzari DE, Brown D, Brar S, Choi JW, et al.; SYMPLICITY HTN-3 Investigators. An analysis of the blood pressure and safety outcomes to renal denervation in African Americans and Non-African Americans in the SYMPLICITY HTN-3 trial. J Am Soc Hypertens 2015;9:769-79.

9. Bhatt DL, Kandzari DE, O'Neill WW, D'Agostino R, Flack JM,
Katzen BT, et al. A controlled trial of renal denervation for resistant hypertension. N Engl J Med 2014;370:1393-401.

10. Vink EE, Goldschmeding R, Vink A, Weggemans C, Bleijs RL, Blankestijn PJ. Limited destruction of renal nerves after catheter-based renal denervation: results of a human case study. Nephrol Dial Transplant 2014;29:1608-10.

11. Choe WS, Song WH, Jeong CW, Choi EK, Oh S. Anatomic conformation of renal sympathetic nerve fibers in living human tissues. Sci Rep 2019;9:4831.

12. Atherton DS, Deep NL, Mendelsohn FO. Micro-anatomy of the renal sympathetic nervous system: a human postmortem histologic study. Clin Anat 2012;25:628-33.

13. Tarzamni MK, Nezami N, Rashid RJ, Argani H, Hajealioghli P, Ghorashi S. Anatomical differences in the right and left renal arterial patterns. Folia Morphol (Warsz) 2008;67:104-10.

14. Olsen LK, Kamper AL, Svendsen JH, Feldt-Rasmussen B. Renal denervation. Eur J Intern Med 2015;26:95-105.

15. Ye E, Baik J, Lee S, Ryu SY, Yang S, Choi EK, et al. Design and simulation of novel laparoscopic renal denervation system: a feasibility study. Int J Hyperthermia 2018;35:9-18.

16. Gill IS. Retroperitoneal laparoscopic nephrectomy. Urol Clin North Am 1998;25:343-60.

17. Kuntz C, Wunsch A, Bödeker C, Bay F, Rosch R, Windeler J, et al. Effect of pressure and gas type on intraabdominal, subcutaneous, and blood pH in laparoscopy. Surg Endosc 2000;14:36771.

18. Gettman MT, Box G, Averch T, Cadeddu JA, Cherullo E, Clayman RV, et al. Consensus statement on natural orifice transluminal endoscopic surgery and single-incision laparoscopic surgery: heralding a new era in urology? Eur Urol 2008;53:111720.

19. Lee JK, Oh JJ, Lee S, Lee SB, Byun SS, Lee SE, et al. A new sliding-loop technique in renorrhaphy for partial nephrectomy: a feasibility study in a porcine model. Surg Innov 2016;23:130-3.

20. Jung JW, Cha WH, Lee BK, Lee S, Lee SB, Lee SE, et al. Laparoendoscopic single-site surgery using innovative articulating instruments: preclinical evaluation of the prototype. J Endourol 2014;28:281-5.

21. Choi EK, Shen MJ, Han S, Kim D, Hwang S, Sayfo S, et al. Intrinsic cardiac nerve activity and paroxysmal atrial tachyarrhythmia in ambulatory dogs. Circulation 2010;121:2615-23.

22. Táborský M, Richter D, Tonar Z, Kubíková T, Herman A, Peregrin J, et al. Early morphologic alterations in renal artery wall and renal nerves in response to catheter-based renal denervation procedure in sheep: difference between single-point and multiple-point ablation catheters. Physiol Res 2017;66:601-14. 